\title{
Hidrogeoquímica e índice de saturação dos minerais no sistema aqüífero do Alto Cristalino de Salvador, Bahia
}

\author{
Sérgio Augusto de Morais Nascimento ${ }^{1}$, Johildo Salomão Figueiredo Barbosa ${ }^{2}$, Manoel Jerônimo \\ Moreira Cruz ${ }^{3}$ \& Cristiane Maciel de Lima ${ }^{4}$
}

\begin{abstract}
Resumo O alto cristalino de Salvador-Bahia tem no seu subsolo rochas cristalinas metamorfizadas e fraturadas, cobertas por um espesso manto regolítico e pela Formação Barreiras, constituindo um aqüífero confinado, heterogêneo e anisotrópico, misto e interdependente, do tipo fissural e intergranular. As águas subterrâneas das coberturas são normalmente cloretadas sódicas enquanto que as mais profundas situadas no embasamento cristalino fissural são bicarbonatada sódica e cálcicas-magnesianas. Todas são águas doces com baixo conteúdo salino, predominando o sódio e o cloreto, devido a influência dos aerossóis marinhos. Os carbonatos aragonita, calcita e dolomita apresentam-se supersaturados nas águas do embasamento cristalino, enquanto que a gibsita apresenta índices de saturação positivos nas coberturas regolíticas. A hematita e a goetita apresentam-se em condições de supersaturação tanto nas coberturas quanto no embasamento fissural produzindo incrustações ferruginosas nos poços tubulares quando perfurados nesses dois ambientes hidrogeoquímicos. O manganês é muito freqüente nas águas subterrâneas da região, ocorrendo dissolvido sob a forma de $\mathrm{Mn} 2+\mathrm{e}$ em condições de subsaturação tanto nas coberturas quanto no aqüífero cristalino fissural, não havendo, portanto possibilidade de se precipitar sob a forma de pirolusita e manganita.
\end{abstract}

Palavras-chave: índice de saturação, hidroquimica, tipos de água subterrânea.

\begin{abstract}
Hydrogeochemical and saturation index of minerals in the aquifer of the Alto Cristalino Salvador, Bahia, Brazil. The high crystalline of Salvador-Bahia is in its subsoil metamorfic and fractured crystalline rocks, covered by a thick mantle Regolithic and the Barreiras Formation, an aquifer is confined, heterogeneous and anisotropic, mixed and interdependent, such fissural and intergranular. Groundwater of coverage are usually sodium chloride while the deeper located in the basement crystalline fissural bicarbonated are sodium and calcium-magnesium. All are fresh water with low salt content, mainly sodium and chloride, due to the influence of marine aerosols. The aragonite carbonates, calcite and dolomite are found in supersaturated waters the crystalline basement, while the rates of saturation gibsita give positive coverage in the regolith. The hematite and goethite were in supersaturated both in terms of coverage in the basement fissural producing iron fouling in wells drilled in these two environments when geochemistry water. The manganese is very common in groundwater in the region, occurring in the form of dissolved Mn2+ and subsaturated both in terms of coverage as the crystalline aquifer fissural, no, so ability to precipitate in the form of pirolusite and manganite.
\end{abstract}

Keywords: saturation index, hydrochemistry, types of groundwater.

INTRODUÇÃO A cobertura regolítica que recobre o embasamento cristalino de Salvador geralmente possui cor avermelhada com presença de argilominerais do grupo da caolinita e minerais aluminosos principalmente a gibsita, sendo produtos da alteração química dos plagioclásios, microclina e outros minerais aluminosos em uma região caracterizada pelo clima chuvoso, quente e úmido. Os minerais ferromagnesianos (biotita, hornblenda, granadas, ortopiroxênios) também dão origem aos minerais argilosos em maior ou menor quantidade e proporcionam a formação dos diversos óxidos e hi- dróxidos de ferro responsáveis pela coloração vermelha do regolito. Alguns minerais de ferro presentes em pequenas quantidades nas rochas cristalinas, tais como pirita, magnetita e ilmenita, quando alterados intempericamente também ajudam a imprimir essa coloração avermelhada, devido à formação da hematita e goetita. Quando predomina a hematita, o regolito é mais avermelhado, enquanto a goetita imprime neles uma cor vermelho-amarelada.

A presença desses minerais secundários formados no regolito evidencia a existência de um estado

1 - Departamento de Geologia e Geofísica Aplicada, Instituto de Geociências da Universidade Federal da Bahia, Salvador (BA), Brasil.

2 - E-mail: sergiomn@ufba.br

Centro de Pesquisa em Geofísica e Geologia, Instituto de Geociências da Universidade Federal da Bahia, Salvador (Ba), Brasil. E-mail: johildo@cpgg.ufba.br

3 - Departamento de Geoquímica, Inst. Geociências da Universidade Federal da Bahia, Salvador (Ba), Brasil. E-mail: jeronimo@ufba.br

4 - Programa de Pós-Graduação em Geologia do Instituto de Geociências da Universidade Federal da Bahia, Salvador (Ba), Brasil E-mail:

ds_Cris@yahoo.com.br 
de supersaturação de alumínio e ferro nas águas subterrâneas que circulam nessa cobertura. $\mathrm{O}$ ferro se constitui num problema sério de contaminação dessas águas, sendo muitas vezes à depender do seu teor, impróprias para o consumo humano. Apesar de o organismo humano necessitar de $19 \mathrm{mg} /$ litro de ferro/dia, os padrões de potabilidade exigem que uma água de abastecimento público para consumo humano, não ultrapasse $0,3 \mathrm{mg} /$ litro de ferro. Este limite foi estabelecido em função de problemas estéticos relacionados á presença desse metal na água e do sabor ruim - sabor de ferrugem, que o ferro lhe confere, fazendo o consumidor recusála. Águas ferruginosas possibilitam o crescimento de ferrobactérias que podem causar problemas para a saúde humana. $\mathrm{O}$ teor alto de ferro no organismo humano pode ser responsável pela formação de radicais livres, muitos dos quais carcinogênicos. A sua presença em água potável favorece o aparecimento de microorganismos patogênicos, que necessitam de ferro para se desenvolver. É sabido que a sua presença influencia a absorção de cobre e chumbo no organismo humano. Quando se apresentam em concentrações acima de 300 $\mu \mathrm{g} /$ litro, mancham louças sanitárias e roupas quando da sua lavagem, produzindo com o tempo uma crosta ferruginosa nos revestimentos e tubulações dos poços.

Para investigar a formação dos minerais secundários de ferro e alumínio procurou-se primeiramente caracterizar ionicamente os diversos tipos de água subterrânea, bem como, as suas características físicoquímicas e ambientais ( $\mathrm{pH}$ e Eh) nas coberturas e no cristalino fissural. Foi necessária a execução do modelamento hidrogeoquimico com o programa PHREEQC 2.0 para verificar os valores do índice de saturação do ferro e alumínio, incluindo-se ainda nesses cálculos o manganês muito comum nas águas que circulam nos sedimentos da Formação Barreiras e os carbonatos/bicarbonatos comuns em aqüíferos cristalinos de natureza fissural.

CARACTERIZAÇÃO DA ÁREA ESTUDADA O município de Salvador está situado entre as coordenadas geográficas $12^{\circ} 53^{\prime} 54^{\prime}$ " e $13^{\circ} 00^{\prime} 59^{\prime}$ "de latitude sul

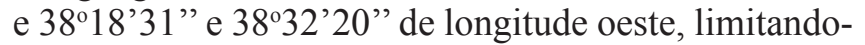
se ao sul e leste com o Oceano Atlântico e a oeste com a Baia de Todos os Santos. Ele abrange uma área em torno de $308,15 \mathrm{~km}^{2}$, sendo que $244 \mathrm{~km}^{2}$ forma o "Alto Cristalino". Os domínios municipais ocupam uma parte continental e outra insular, com três ilhas situadas na Baía de Todos os Santos e subordinadas a sua jurisdição administrativa.

Do ponto de vista hídrico superficial, as principais bacias hidrográficas da porção continental são: Camarujipe com $52 \mathrm{~km}^{2}$, Cobre com $17 \mathrm{~km}^{2}$, Ipitanga com $59 \mathrm{~km}^{2}$, Jaguaribe com $58 \mathrm{~km}^{2}$, Lucaia com $18 \mathrm{~km}^{2}$ e rio das Pedras/Pituaçu com $28 \mathrm{~km}^{2}$. Em escala regional o sistema de drenagem é dendrítico, tendo as suas nascentes situadas no planalto costeiro dissecado, com o fluxo de água dos rios migrando em direção ao Oceano Atlântico, com exceção das águas da bacia do Cobre que correm em direção a Baia de Todos os Santos.
Este artigo visa apresentar os resultados das pesquisas realizadas para determinação das características hidrogeoquímicas do manancial hídrico subterrâneo do Alto Cristalino de Salvador.

O Alto Cristalino de Salvador é geologicamente formado (Fig. 1): a) pelo embasamento cristalino fissural onde estão presentes rochas metamórficas ortoderivadas, compostas de granulitos charnoenderbíticos e tonalíticos, ambos contendo enclaves ultramáficos (metapiroxenitos) e máficos (metagabros), sendo cortadas por monzo-sienogranitos e diques máficos (Barbosa et al. 2005). Ocorre também, um grupo de rochas metamórficas paraderivadas alumino-magnesianas associadas a granulitos básicos e quartzitos. A leste da região, onde as elevações são menores, encontram-se rochas monzoníticas-monzodioríticas e um conjunto de rochas gnáissicas, graníticas, anfibolíticas e migmatíticas, todas reequilibradas na fácies anfibolito/granulito. O sistema de fraturamento ortogonal $\mathrm{N} 30-40^{\circ}$ e N130-140 constituem vias efetivas de percolação e possibilitam o ataque químico dos principais minerais formadores das rochas e acessórios, formando um solo residual e a rocha alterada (saprolito) que constituem o regolito sobreposto ao embasamento cristalino; b) pela cobertura regolítica, que geralmente possui cor avermelhada e composição dominantemente argilosa (teores de argila $>35 \%$ ). Esses argilominerais são produtos de alteração química dos plagioclásios, microclina e outros minerais aluminosos que compõem as rochas do embasamento cristalino, quando em contato com as águas subterrâneas. Os minerais ferromagnesianos (biotita, hornblenda, granadas, ortopiroxênios) também dão origem aos minerais argilosos em maior ou menor quantidade e proporcionam a formação dos diversos óxidos e hidróxidos de ferro responsáveis pela coloração vermelha dos solos. Alguns minerais de ferro presentes em pequenas quantidades nas rochas cristalinas, tais como pirita, magnetita e ilmenita, quando alterados, também ajudam a imprimir essa coloração avermelhada, devido a formação da hematita e goetita, depois que os seus produtos amorfos foram desidratados. Quando predomina a hematita, os solos são mais avermelhados, enquanto a goetita imprime neles uma cor vermelho-amarelada; c) pela Formação Barreiras que é formada de arenitos argilosos de coloração vermelha, violeta, branca e amarela, com estratificações plano-paralelas e cruzadas. São freqüentes as intercalações de siltitos e argilas coloridas, bem como lentes conglomeráticas e cauliníticas. Os conglomerados são compostos comumente de fenoclastos de quartzo leitoso, subarredondados, em meio a seixos de granulitos, arenitos e lamitos, distribuídos numa matriz arenosa mal selecionada, igualmente complexa em composição (Martin et al. 1980 in IBGE 1999). As litologias da Formação Barreiras são em geral friáveis, sendo comum a presença de concreções ferruginosas, formando massas compactas no seio de uma matriz areno-argilosa castanho avermelhada.

Segundo dados obtidos em dezenas de poços tubulares, a cobertura regolítica sobre o embasamento cristalino tem uma espessura média de $20 \pm 2,5$ me- 

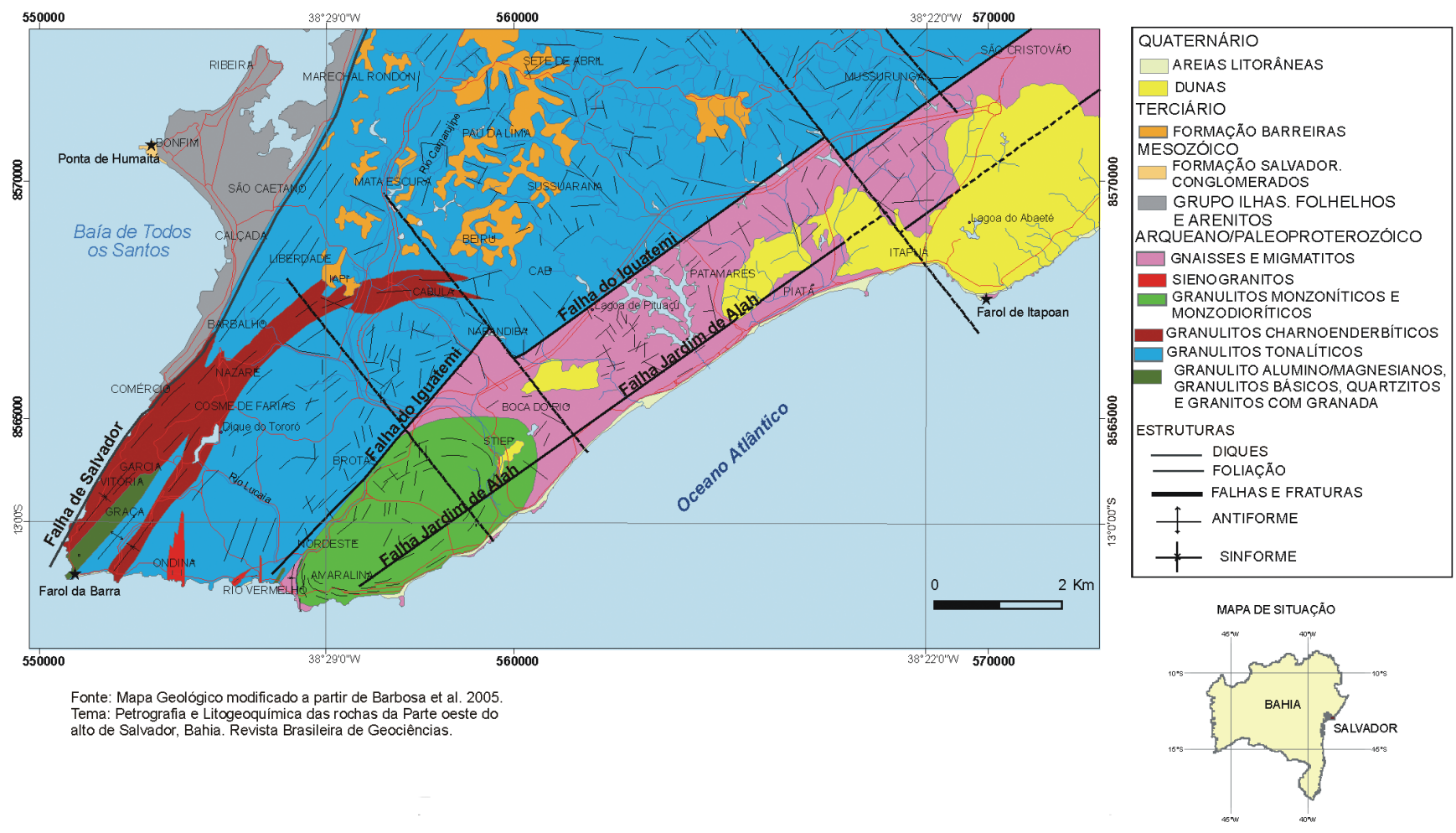

Figura 1 - Mapa geológico de Salvador.

tros. A cobertura regolítica e o cristalino formam de um modo geral um sistema aqüífero confinado, com o nível estático pouco profundo, apresentando um valor médio de 5,4 metros de profundidade, podendo variar estatisticamente de 4,0 a 7,0metros, considerando um intervalo de confiança de $95 \%$ e $\mathrm{n}=98$ observações (Nascimento 2008).

MATERIAIS E MÉTODOS Nesta pesquisa foram selecionados nove poços tubulares de captação de água subterrânea, sendo cinco no embasamento cristalino fissural e quatro nos sedimentos da Formação Barreiras, além de cinco fontes naturais situadas na cobertura regolítica (Fig. 2). Esses foram previamente cadastrados, identificados nas cartas topográficas na escala 1/2000 e georreferenciados no terreno com GPS (Global Position System). A coleta de informações dos poços tubulares foi feita nos arquivos das empresas perfuradoras, enquanto que as informações das fontes foram obtidas nos locais de amostragem.

A amostragem de água nos poços tubulares foi realizada depois desses terem sido bombeados por cerca de 10 a 20 minutos, tempo suficiente para sua renovação e, no caso das fontes naturais, foram escolhidas aquelas que estavam em atividade constante e, portanto, apresentando fluxo contínuo e ininterrupto.

Durante a amostragem de campo foram feitas anotações em fichas padronizadas e efetuadas medidas de $\mathrm{pH}$, Eh, temperatura, condutividade elétrica, oxigênio dissolvido absoluto, relativo e salinidade, utilizando-se um medidor portátil multiparâmetros 340 i /SET da WTW. À medida que a coleta de água subterrânea se desenvolvia, as amostras eram acondicionadas em caixas de isopor com gelo e remetidas no mesmo dia para os laboratórios da Embasa-Empresa Baiana de Agua e Saneamento, onde foram efetuadas as análises. No laboratório as amostras foram filtradas em membrana de 0,45 micra, utilizando-se de manifold à vácuo e posteriormente preservadas com ácido nítrico à $\mathrm{pH}<2,0$.

Para a determinação dos parâmetros físicos e químicos, utilizou-se os metodos apropriadas para cada tipo de análise, de acordo com os manuais do Standard Methods of Water and Wasterwater (American Public Health Association 1998) e da Varian Indústria e Comércio Ltda. fabricante dos aparelhos de Espectrometria de Absorção Atômica SpectrAA 220 Z com forno de grafite e SpectrAA 220, cujos resultados encontram-se na tabela 1 .

Para a classificação hidroquímica foi utilizado o diagrama triangular de Piper (1944) com os valores dos componentes maiores, $\mathrm{Ca}^{++}, \mathrm{Mg}^{++}, \mathrm{Na}^{+}, \mathrm{K}^{+}, \mathrm{Cl}^{-}, \mathrm{HCO}_{3}^{-2}$, e $\mathrm{SO}_{4}^{-2}$, elaborado através do programa Qualigraf da Fundação Cearence de Meteorologia.

Para a obtenção dos valores dos índices de saturação (SI) em cada ponto de amostragem, utilizaram-se os parâmetros que envolvem as condições ambientais tais como: $\mathrm{pH}$, Eh, densidade da água e temperatura. Além desses, foram utilizados os elementos maiores cálcio, magnésio, sódio, potássio, sulfato, cloreto, bicarbonato, ferro, sílica, além dos elementos menores manganês, alumínio, bário e zinco.

Para efetuar a modelagem hidrogeoquímica utilizou-se o programa PHREEQC 2.0 (Department of Geosciences North Dakota State University 2007). O 


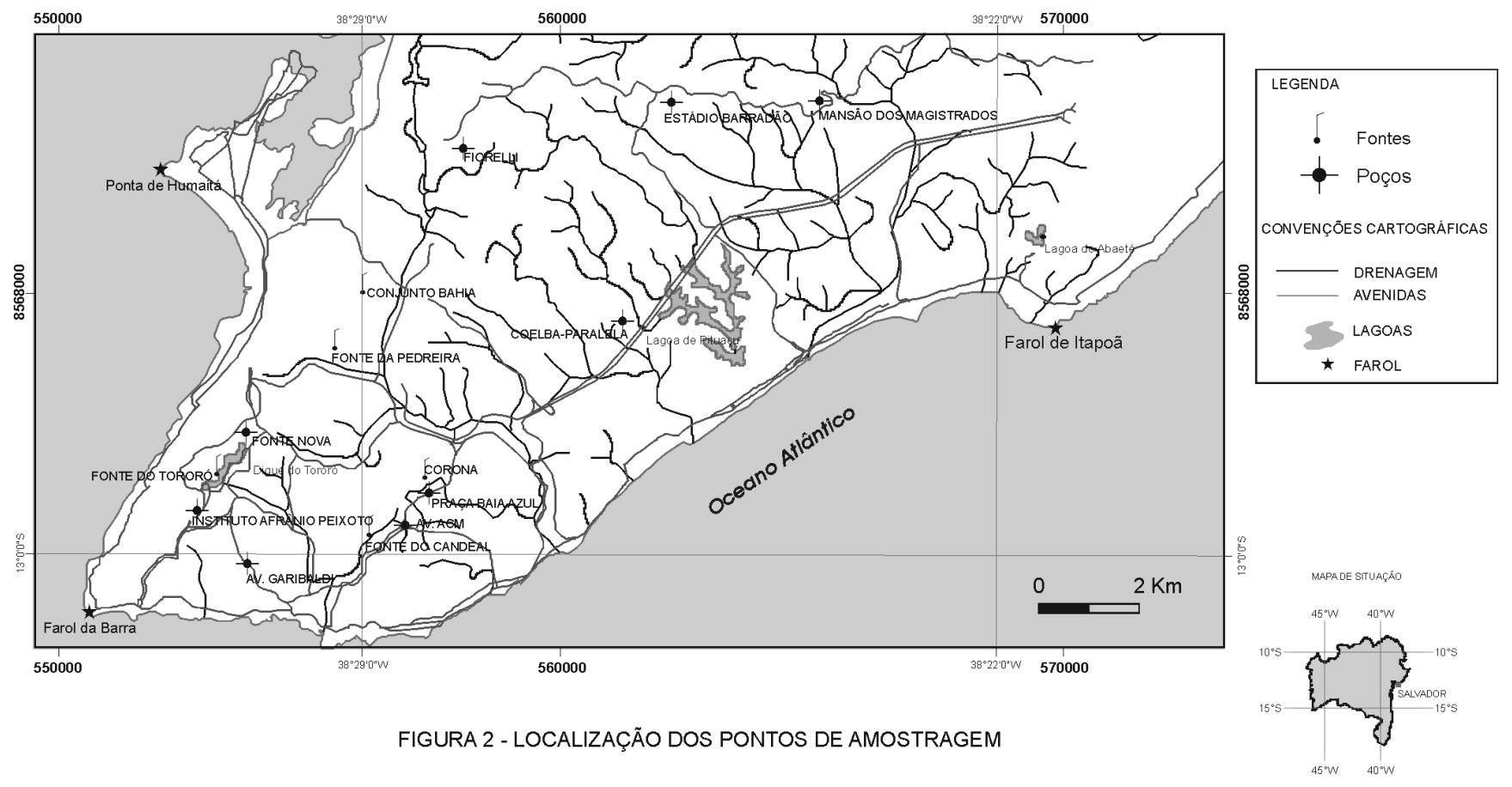

Figura 2 - Localização dos pontos de amostragem

Tabela 1 - Resultados analiticos da água subterrânea do AltoCristalino de Salvador.

\begin{tabular}{c|c|c|c|c|c|c|c|c|c|c|c|c|c|c|c}
\hline Pontos & $\mathrm{PH}$ & $\mathrm{Eh}$ & $\mathrm{Ca}$ & $\mathrm{Mg}$ & $\mathrm{Na}$ & $\mathrm{K}$ & $\mathrm{HCO} 3$ & $\mathrm{SO} 4$ & $\mathrm{Cl}$ & $\mathrm{Al}$ & $\mathrm{Ba}$ & $\mathrm{Fe}$ & $\mathrm{Mn}$ & $\mathrm{SiO} 2$ & $\mathrm{Zn}$ \\
\hline & -- & $\mathrm{mV}$ & $\mathrm{mg} / \mathrm{L}$ & $\mathrm{mg} / \mathrm{L}$ & $\mathrm{mg} / \mathrm{L}$ & $\mathrm{mg} / \mathrm{L}$ & $\mathrm{mg} / \mathrm{L}$ & $\mathrm{mg} / \mathrm{L}$ & $\mathrm{mg} / \mathrm{L}$ & $\mathrm{mg} / \mathrm{L}$ & $\mathrm{mg} / \mathrm{L}$ & $\mathrm{mg} / \mathrm{L}$ & $\mathrm{mg} / \mathrm{L}$ & $\mathrm{mg} / \mathrm{L}$ & $\mathrm{mg} / \mathrm{L}$ \\
\hline 2 & 6,70 & 247,00 & 13,00 & 15,10 & 62,80 & 4,10 & 178,00 & 17,40 & 60,80 & 0,0568 & 0,0989 & 0,04930 & 0,4680 & 20,00 & 0,0073 \\
\hline 3 & 7,30 & 177,00 & 8,20 & 5,20 & 103,00 & 5,40 & 181,00 & 19,20 & 49,40 & 0,0204 & 0,0920 & 0,06460 & 0,0413 & 64,00 & 0,0078 \\
\hline 4 & 7,20 & 80,00 & 14,00 & 7,38 & 55,90 & 3,40 & 117,00 & 14,60 & 43,20 & 0,0973 & 0,1520 & 0,05480 & 0,1340 & 23,00 & 0,188 \\
\hline 6 & 5,40 & 276,00 & 6,70 & 17,20 & 72,80 & 2,70 & 13,70 & 10,30 & 118,00 & 0,1270 & 0,4550 & 0,05600 & 0,0822 & 44,00 & 0,0196 \\
\hline 7 & 5,30 & 257,00 & 11,00 & 11,50 & 39,60 & 4,90 & 12,70 & 18,50 & 55,30 & 0,0164 & 0,2060 & 0,05240 & 0,0720 & 9,00 & 0,0039 \\
\hline 11 & 5,30 & 263,00 & 15,00 & 13,70 & 37,80 & 6,50 & 16,50 & 32,00 & 54,80 & 0,0323 & 0,3080 & 0,05451 & 0,0200 & 22,00 & 0,0111 \\
\hline 12 & 6,50 & 203,00 & 36,00 & 22,40 & 30,70 & 8,00 & 154,00 & 9,57 & 42,10 & 0,0155 & 0,4040 & 0,04470 & 0,0200 & 57,00 & 0,003 \\
\hline 15 & 6,80 & 177,00 & 46,00 & 25,80 & 31,10 & 6,30 & 169,00 & 23,30 & 57,80 & 0,0206 & 0,3020 & 0,05740 & 0,0200 & 35,00 & 0,003 \\
\hline 20 & 4,90 & 278,00 & 19,00 & 6,71 & 45,80 & 5,00 & 5,95 & 20,30 & 57,80 & 0,1450 & 0,1920 & 0,02210 & 0,1100 & 12,00 & 0,003 \\
\hline 22 & 5,40 & 223,00 & 27,00 & 5,46 & 45,30 & 11,00 & 6,94 & 42,00 & 63,20 & 0,2830 & 0,1260 & 0,05120 & 0,2110 & 1,00 & 0,003 \\
\hline 27 & 5,20 & 145,00 & 4,00 & 2,53 & 12,10 & 1,10 & 14,90 & 10,30 & 25,50 & 0,0177 & 0,0413 & 3,79800 & 0,5950 & 9,30 & 0,003 \\
\hline 28 & 5,60 & 270,00 & 2,10 & 2,79 & 12,10 & 2,00 & 12,40 & 6,26 & 23,50 & 0,1160 & 0,0942 & 0,06850 & 1,1200 & 19,00 & 0,0035 \\
\hline 29 & 5,20 & 271,00 & 1,50 & 2,93 & 14,10 & 1,00 & 7,44 & 5,00 & 23,50 & 0,0118 & 0,0380 & 0,04330 & 0,0200 & 6,30 & 0,0031 \\
\hline 31 & 5,20 & 312,00 & 2,20 & 4,29 & 19,50 & 1,10 & 12,40 & 5,00 & 26,40 & 0,0457 & 0,0380 & 0,05200 & 0,0797 & 11,00 & 0,0075 \\
\hline
\end{tabular}

PHREEQC 2.0 é um programa de computador projetado para executar uma ampla variedade de cálculos hidrogeoquímicos de baixa temperatura. O PHREEQC é fundamentado no modelo de associações iônicas em meio aquoso sendo capaz de realizar cálculos de especiação e índices de saturação entre outros.

\section{RESULTADOS OBTIDOS}

Tipos e classificação das águas subterrânea Os tipos de água subterrâneas obtidas nos pontos de captação investigados são principalmente cloretadas-sódicas $(64,4 \%)$ (Fig. 3) e ocorrem nas coberturas constituídas pelos sedimentos da Formação Barreiras e regoliticas desenvolvidas sobre o embasamento cristalino. Essas águas de natureza cloretada-sódica se originam da dissolução de aerossóis marinhos, trazidos por correntes atmosféricas, que entram no aqǘf́ero através da recarga com baixas concentrações de cloro e sódio, haja vista a baixa condutividade elétrica da água subterrânea na região (média de $400 \mu \mathrm{S} / \mathrm{cm}$ ). Em $21 \%$ dos pontos de captação pesquisados a água subterrânea é do tipo bicarbonatada sódica (Tab. 2) com relações iônicas do tipo $\mathrm{rNa}>\mathrm{rMg}>\mathrm{rCa}$ e bicarbonatada cálcica-magnesiana com relações iônicas do tipo $\mathrm{rMg}>\mathrm{rCa}>\mathrm{Na}$, 


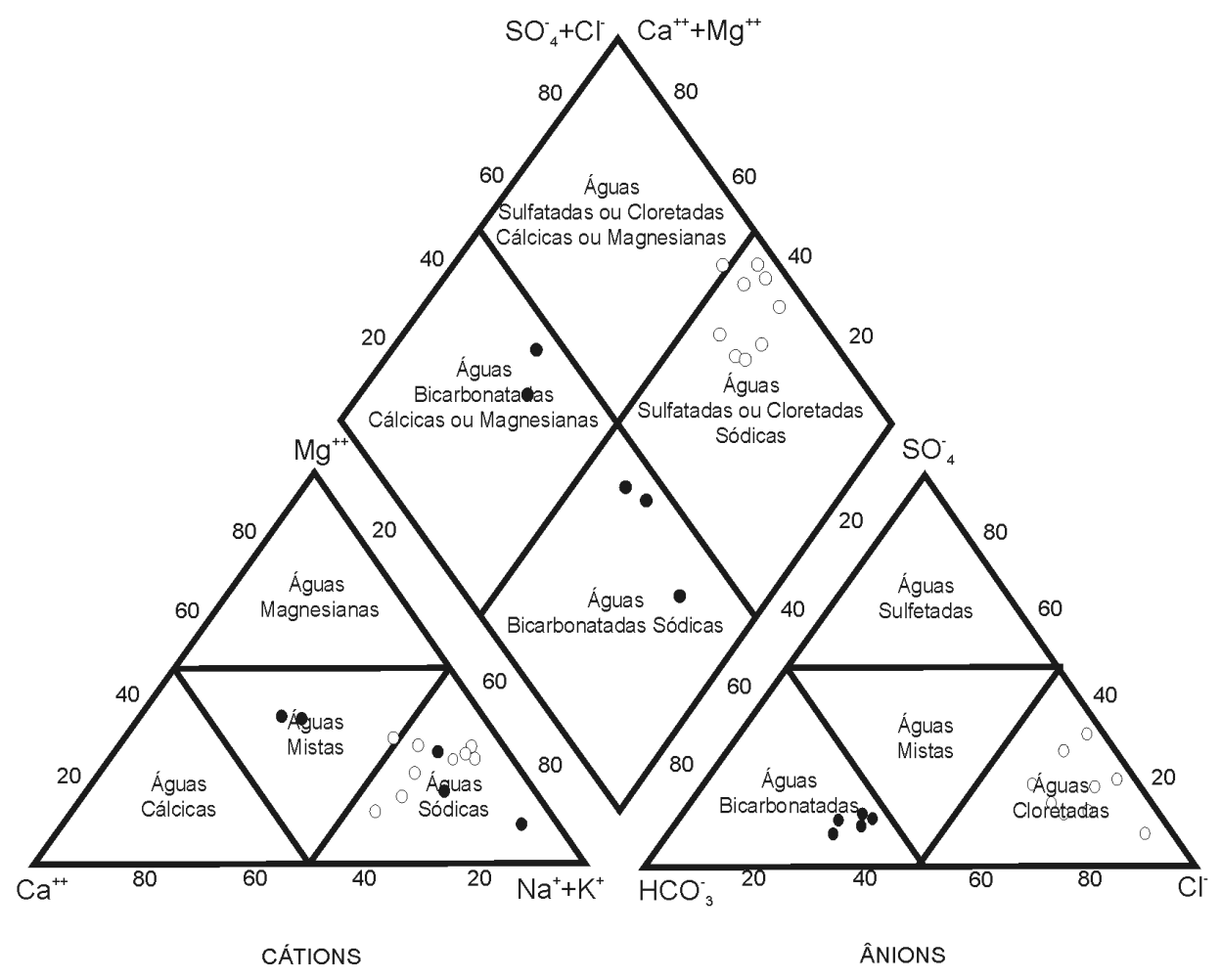

Figura 3 - Diagrama Triangular de Piper.

$\mathrm{rNa}>\mathrm{rCa}>\mathrm{rMg}, \mathrm{rCa}>\mathrm{rMg}>\mathrm{rNa}$ com $\mathrm{rHCO} 3>\mathrm{rCl}>\mathrm{rSO}_{4}$ e estão localizadas no sistema cristalino fissural. $\mathrm{Em}^{4}$ $64,3 \%$ dos pontos, a água subterrânea encontrada é de natureza cloretada-sódica com relações iônicas do tipo $\mathrm{rNa}>\mathrm{rMg}>\mathrm{rCa}$ com $\mathrm{rCl}>\mathrm{rHCO}_{3}>\mathrm{SO}_{4}$ além de $\mathrm{rNa}>\mathrm{rMg}>\mathrm{rCa}$ e $\mathrm{rNa}>\mathrm{rCa}>\mathrm{rMg}$ com $\mathrm{rCl}>\mathrm{rSO}_{4}>\mathrm{rHCO}_{3}$ sendo encontradas nas coberturas regolíticas e nos sedimentos da Formação Barreiras Assim, o cátion predominante nas águas subterrâneas da área pesquisada é o sódio, enquanto o cloreto representa o anion que ocorre com maior freqüência.

Modelagem hidrogeoquímica - especiação Para a determinação do índice de saturação (SI) o programa PHREEQC 2.0 efetuou cálculos da concentração molar, atividade iônica e do coeficiente de atividade das espécies químicas na água subterrânea do Alto Cristalino de Salvador. Em seguida obteve os valores dos índices de saturação (SI) da fase sólida de vários minerais em equilíbrio com a solução aquosa nos 14 pontos amostrados. O PHREEQC 2.0 apresenta no final o valor do produto da atividade iônica (IAP) dos componentes analisados dividido pela constante de equilíbrio termodinâmica $(\mathrm{K})$ a uma temperatura $(\mathrm{t})$. Para facilitar a leitura e interpretação dos resultados o programa apresenta os cálculos do índice de saturação (SI) em valores logarítmicos, ou seja: $\log \mathrm{SI}=\log \mathrm{IAP}-\log \mathrm{Kt}$ (Tab. 3). Quando os valores de SI são positivos existem condições de supersaturação das espécies químicas havendo com isso a possibilidade de formação da fase sólida mineral a partir da solução aquosa através de uma reação química inversa, enquanto os negativos representam uma solução subsaturada, sem condições de formação da fase sólida mineral. Quando o SI é igual a zero a solução está em equilíbrio químico, ou seja, a velocidade da reação direta (fase sólida mineral -> solução) é igual à reação inversa (solução $\rightarrow$ fase sólida mineral)

Devido as incertezas inerentes ao cálculo do índice de saturação (SI), em função dos resultados muitas vezes duvidosos das análises químicas e do cálculo do valor da constante de equilíbrio do mineral em processo de dissolução, recomenda-se por motivo de segurança que os valores do SI considerados estejam acima de 0 (zero) $\pm 0,5$ (Deutsch 1997).

CARBONATOS As condições de saturação e formação desses carbonatados, a partir das águas subterrâneas ficaram mais evidenciadas no sistema aqüífero fissural, ou seja, nos pontos de captação 2 (Av. Garibaldi), 3 (Pr. Baia Azul), 4 (Av. ACM), 12 (I. Afrânio Peixoto) e 15 (Estádio da Fonte Nova) (Tab. 3). A elevação do $\mathrm{pH}$ para valores acima de 6,5 nesses pontos (Fig. 4) faz aumentar o índice de saturação do bicarbonato na água do aqǘffero fissural e, consequentemente, a precipitação da fase sólida mineral através de reações químicas inversas sob a forma de aragonita, calcita e dolomita.

Em análises por difratometria de raios-X do material em suspensão, presente na água subterrânea em dois poços tubulares localizados respectivamente no Condomínio Jardim Piatã e Jornal Correio da Bahia, foi constatado a presença de calcita e dolomita (Nascimento 2008).

As águas subterrâneas existentes na cobertura 
Tabela 2 - Tipo e classificação da águas subterrâneas.

\begin{tabular}{|c|c|c|c|c|}
\hline PONTO & LOCAL & TIPO DE ÁGUA & CLASSIFICAÇÃO & AQUIFERO \\
\hline 2 & Av. Garibaldi & $\mathrm{Na}-\mathrm{Mg}-\mathrm{HCO}_{3}-\mathrm{Cl}$ & bicarbonatada sódica & Fissural \\
\hline 3 & Praça Baia Azul & $\mathrm{Na}-\mathrm{HCO}_{3}-\mathrm{Cl}$ & bicarbonatada sódica & Fissural \\
\hline 4 & Av. ACM & $\mathrm{Na}-\mathrm{HCO}_{3}-\mathrm{Cl}$ & bicarbonatada sódica & Fissural \\
\hline 6 & Corona & $\mathrm{Na}-\mathrm{Mg}-\mathrm{Cl}$ & cloretada sódica & Regolito \\
\hline 7 & Fonte do Candeal & $\mathrm{Na}-\mathrm{Mg}-\mathrm{Cl}$ & cloretada sódica & Regolito \\
\hline 11 & Fonte do Tororó & $\mathrm{Na}-\mathrm{Mg}-\mathrm{Ca}-\mathrm{Cl}$ & cloretada sódica & Regolito \\
\hline 12 & Instituto Afrânio. Peixoto & $\mathrm{Mg}-\mathrm{Ca}-\mathrm{Na}-\mathrm{HCO}_{3}-\mathrm{Cl}$ & $\begin{array}{l}\text { Bicarbonatada } \\
\text { calco-magnesiana }\end{array}$ & Fissural \\
\hline 15 & Fonte Nova & $\mathrm{Ca}-\mathrm{Mg}-\mathrm{Na}-\mathrm{HCO} 3-\mathrm{Cl}$ & $\begin{array}{l}\text { bicarbonatada } \\
\text { calco-magnesiana }\end{array}$ & Fissural \\
\hline 20 & Conjunto Bahia & $\mathrm{Na}-\mathrm{Ca}-\mathrm{Cl}$ & cloretada sódica & Regolito \\
\hline 22 & Fonte da Pedreira & $\mathrm{Na}-\mathrm{Ca}-\mathrm{Cl}-\mathrm{SO} 4$ & cloretada sódica & Regolito \\
\hline 27 & Fiorelli & $\mathrm{Na}-\mathrm{Cl}$ & cloretada sódica & $\begin{array}{l}\text { Formação } \\
\text { Barreiras }\end{array}$ \\
\hline 28 & Estádio Barradão & $\mathrm{Na}-\mathrm{Mg}-\mathrm{Cl}$ & cloretada sódica & $\begin{array}{l}\text { Formação } \\
\text { Barreiras }\end{array}$ \\
\hline 29 & Mansão dos Magi strados & $\mathrm{Na}-\mathrm{Mg}-\mathrm{Cl}$ & cloretada sódica & $\begin{array}{l}\text { Formação } \\
\text { Barreiras }\end{array}$ \\
\hline 31 & Coelba-Paralela & $\mathrm{Na}-\mathrm{Mg}-\mathrm{Cl}$ & cloretada sódica & Regolito \\
\hline
\end{tabular}

Tabela 3 - Índices de saturação (SI) nas águas subterrâneas de alguns poços tubulares e fontes existentes em Salvador.

\begin{tabular}{|c|c|c|c|c|c|c|c|c|c|c|c|}
\hline \multirow{3}{*}{$\begin{array}{l}\text { Pontos } \\
\text { de Cap- } \\
\text { tação }\end{array}$} & \multirow{3}{*}{ Local } & \multirow{3}{*}{$\begin{array}{l}\text { Sistema } \\
\text { Aqüífero }\end{array}$} & \multicolumn{3}{|c|}{ Carbonatos } & \multirow{2}{*}{$\begin{array}{c}\text { Aluminio } \\
\text { Gibsita }\end{array}$} & \multicolumn{3}{|c|}{ Ferro } & \multicolumn{2}{|c|}{ Manganês } \\
\hline & & & Aragonita & Calcita & $\begin{array}{c}\text { Dolo- } \\
\text { mita }\end{array}$ & & Siderita & Hematita & Goetita & $\begin{array}{l}\text { Manga- } \\
\text { nita }\end{array}$ & $\begin{array}{c}\text { Pirolu- } \\
\text { sita }\end{array}$ \\
\hline & & & $\mathrm{CaCO}_{3}$ & $\mathrm{CaCO}_{3}$ & $\begin{array}{l}\mathrm{Ca} \mathrm{Mg} \\
\left(\mathrm{CO}_{3}\right)_{2}\end{array}$ & $\mathrm{Al}(\mathrm{OH})_{3}$ & $\mathrm{FeCO}_{3}$ & $\mathrm{Fe}_{2} \mathrm{O}_{3}$ & $\mathrm{FeOOH}$ & $\mathrm{MnOOH}$ & $\mathrm{MnO}_{2}$ \\
\hline 2 & Av. Garibaldi & Fissural & 0,82 & 0,96 & 2,42 & $-0,49$ & $-5,57$ & 16,00 & 6,99 & $-0,11$ & $-2,34$ \\
\hline 3 & Pr. Baia Azul & Fissural & 0,56 & 0,70 & 1,63 & $-0,85$ & $-4,06$ & 16,33 & 7,15 & $-2,54$ & $-5,95$ \\
\hline 4 & Av. ACM & Fissural & 0,84 & 0,98 & 2,10 & $-0,37$ & $-3,28$ & 15,95 & 6,96 & $-2,97$ & $-7,82$ \\
\hline 6 & $\begin{array}{l}\text { Fonte } \\
\text { Corona }\end{array}$ & Regolito & $-1,28$ & $-1,14$ & $-1,5$ & $\mathbf{0 , 8 3}$ & $-4,85$ & 16,88 & 7,43 & $-1,93$ & $-4,97$ \\
\hline 7 & $\begin{array}{l}\text { Fonte } \\
\text { Candeal }\end{array}$ & Regolito & $-0,51$ & $-0,37$ & $-0,34$ & $-0,69$ & $-6,01$ & 16,44 & 7,21 & $-0,68$ & $-3,25$ \\
\hline 11 & $\begin{array}{l}\text { Fonte do } \\
\text { Tororó }\end{array}$ & Regolito & $-0,41$ & $-0,27$ & $-0,21$ & $-0,23$ & $-5,61$ & 16,61 & 7,30 & $-3,53$ & $-6,24$ \\
\hline 12 & $\begin{array}{l}\text { I. Afrânio } \\
\text { Peixoto }\end{array}$ & Fissural & 1,18 & 1,32 & 2,83 & $-0,93$ & $-4,71$ & 16,08 & 7,03 & $-2,21$ & $-5,49$ \\
\hline 15 & $\begin{array}{l}\text { Estádio } \\
\text { Fonte Nova }\end{array}$ & Fissural & 1,33 & 1,47 & 3,10 & $-0,89$ & $-4,32$ & 16,19 & 7,08 & $-2,59$ & $-6,11$ \\
\hline 20 & $\begin{array}{l}\text { Fonte Conj. } \\
\text { Bahia }\end{array}$ & Regolito & $-1,75$ & $-1,61$ & $-3,30$ & 1,43 & $-4,53$ & 16,06 & 7,02 & $-3,48$ & $-6,92$ \\
\hline 22 & $\begin{array}{l}\text { Fonte da } \\
\text { Pedreira }\end{array}$ & Regolito & $-2,25$ & $-2,11$ & $-4,53$ & 2,30 & $-2,71$ & 15,35 & 6,66 & $-6,09$ & $-10,91$ \\
\hline 27 & Fiorelli & $\begin{array}{l}\text { Form } \\
\text { Barreiras }\end{array}$ & $-1,82$ & $-1,68$ & $-3,18$ & 0,35 & $-0,13$ & 20,31 & 9,14 & $-4,49$ & $-9,82$ \\
\hline 28 & $\begin{array}{l}\text { Estádio } \\
\text { Barradão }\end{array}$ & $\begin{array}{l}\text { Form. } \\
\text { Barreiras }\end{array}$ & $-1,55$ & $-1,41$ & $-2,25$ & 0,32 & $-5,49$ & 16,58 & 7,26 & $-0,65$ & $-2,31$ \\
\hline 29 & $\begin{array}{l}\text { M. } \\
\text { Magistrados }\end{array}$ & $\begin{array}{l}\mathrm{F} \\
\text { Barreiras }\end{array}$ & $-1,58$ & $-1,43$ & $-2,21$ & $-0,75$ & $-6,38$ & 16,35 & 7,17 & $-1,03$ & $-3,50$ \\
\hline 31 & $\begin{array}{l}\text { Coelba/ } \\
\text { Paralela }\end{array}$ & $\begin{array}{l}\mathrm{F} \\
\text { Barreiras }\end{array}$ & $-1,20$ & $-1,06$ & $-1,45$ & $-0,20$ & $-6,79$ & 16,46 & 7,22 & 0,14 & $-1,53$ \\
\hline
\end{tabular}

Fonte: Nascimento 2008.

regolítica e de sedimentos da Formação Barreiras apresentam-se subsaturadas em carbonatos e sem condições para precipitação da aragonita, calcita e dolomita, através de reações químicas inversa.
ALUMÍNIO Os valores positivos do índice de saturação mostram que os processos de alitização com precipitação da $\mathrm{Al}(\mathrm{OH})_{3}$ ocorrem somente na cobertura regolitica evidenciados nos pontos 6 (Fonte Corona), 
20 (Fonte do Conjunto Bahia) e 22 (Fonte da Pedreira) onde as condições ambientais são oxidantes e o pH varia de 4,9 a 5,4 (Fig. 4).

FERRO As águas subterrâneas do Alto Cristalino de Salvador apresentam-se constantemente com um teor de ferro relativamente alto. As condições ambientais da água subterrânea são oxidantes e o pH varia de 4,9 a 7,3 criando as condições necessárias para a precipitação do ferro quando o índice de saturação atinge valores acima de $+0,5$ sob a forma da hematita $\left(\mathrm{Fe}_{2} \mathrm{O}_{3}\right)$ (Fig. 5) e hidróxidos do tipo goetita. Essa precipitação de ferro pode acontecer tanto nas coberturas regolíticas quanto no aqüífero cristalino fissural indistintamente. Se as condições forem redutoras, o ferro pode se precipitar sob a forma de carbonato (siderita), como ocorre em determinados locais de Salvador onde o poço tubular está próximo de zonas de brejo e pântanos (Nascimento 2008).

Os valores positivos do índice de saturação do ferro na água é uma conseqüência da alteração intempérica dos minerais ferromagnesianos das rochas granulíticas, durante os processos pedogenéticos, principalmente os ortopiroxênios, anfibólios e biotitas.

MANGANESS O manganês encontra-se frequentemente dissolvido sob a forma de $\mathrm{Mn}^{2+}$ na água subterrânea de Salvador muitas vezes com teores relativamente altos principalmente nos sedimentos da Formação Barreiras. Os seus índices de saturação mostraram-se negativos (subsaturados) em todos os pontos estudados (Fig. 6), o que aliado às condições de $\mathrm{pH}$ e Eh da água impede a sua precipitação sob a forma de pirolusita $\left(\mathrm{MnO}_{2}\right)$ e manganita $(\mathrm{MnOOH})$, conforme está assinalada na tabela 3. Para precipitar o manganês necessita de um $\mathrm{pH}$ superior a 8,0 - fato que não ocorre nas águas subterrâneas em foco (Tab. 1). Sua origem primária está associada a decomposição intempérica dos minerais ferromagnesianos (ortopiroxênios, anfibólios e biotitas) existentes nas rochas granulíticas do aqüífero cristalino fraturado.

CONCLUSÕES As águas subterrâneas do Alto Cristalino de Salvador são predominantemente do tipo

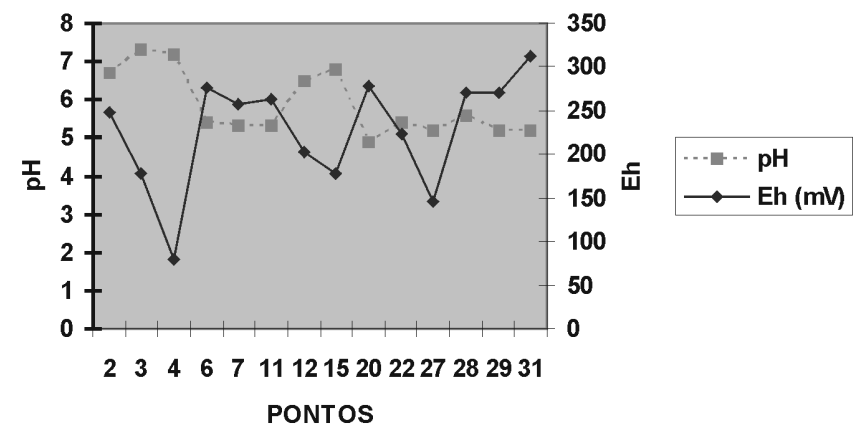

Figura 4 - Variação do pH e Eh na água subterrânea nos pontos amostrados.

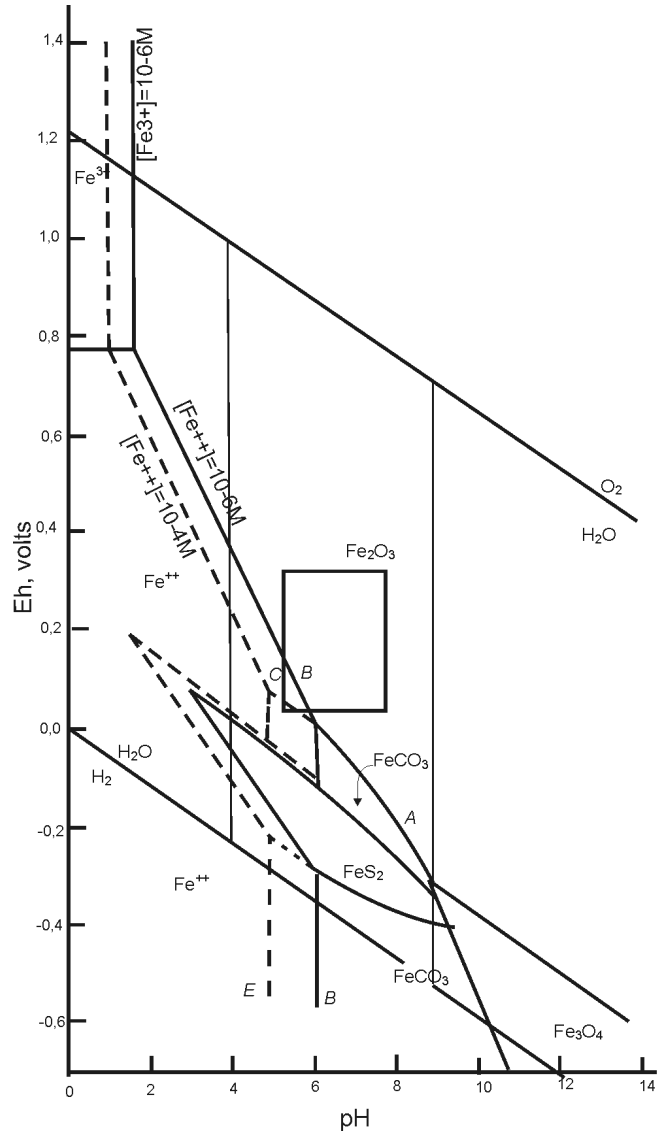

Figura 5 - Diagrama $p H$-Eh para o ferro (Mason 1971).

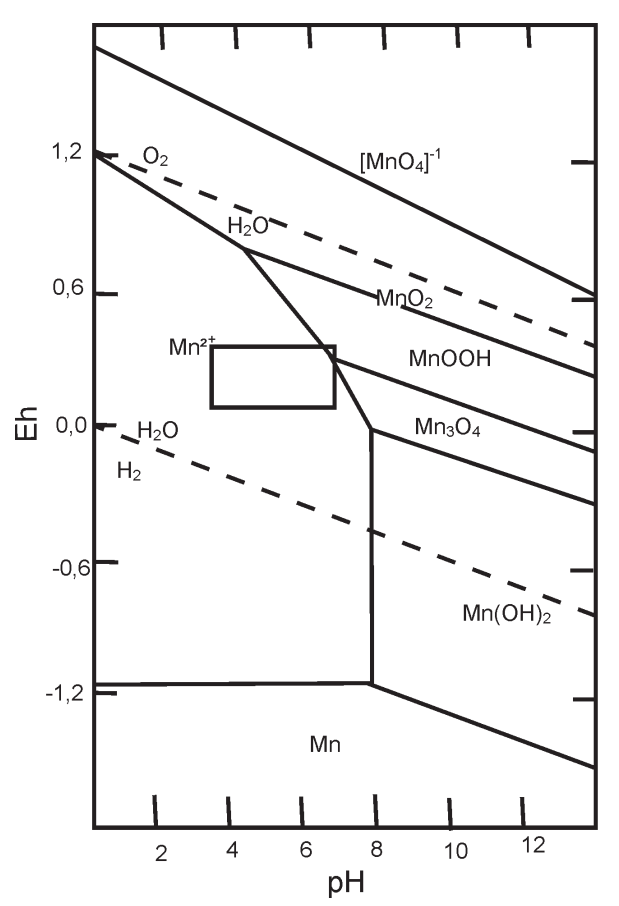

Figura 6 - Diagrama $\mathrm{pH}$ - Eh para o manganês (Mason 1971). 
cloretada sódica nas coberturas regolíticas e nos sedimentos da Formação Barreiras. À medida que elas se infiltram, atingindo as rochas cristalinas fraturadas, evoluem para bicarbonatada sódica e bicarbonatada cálcica-magnesiana ou mistas.

De uma maneira geral, os ions sódio e cloro predominam nas águas subterrâneas devido a influência dos aerossóis marinhos que se incorporam às águas meteóricas no processo de recarga do sistema aqüífero da área estudada.

Os valores do índice de saturação (SI) negativos dos carbonatos (aragonita-calcita-dolomita) nas coberturas e o seu aumento em direção ao sistema cristalino fissural evidenciam condições mais propícias para a sua precipitação devido ao aumento da concentração do bicarbonato no cristalino fissural. A saturação dos carbonatos ao nível do embasamento fissural aumenta do $\mathrm{pH}$ médio para uma faixaque de $6,9 \pm 0,4$, enquanto que nas coberturas ele decresce até para cerca de $5,3 \pm 0,4$. Apesar disso, não existem informações quanto a existência de crostas carbonaticas nas tubulações dos poços, inclusive aqueles que captam água no embasamento cristalino fissural.

O hidróxido de alumínio (gibsita) apresenta índices de saturação elevados e positivos ao nível das coberturas regolíticas e na Formação Barreiras facilitando os processos de alitização nessas coberturas, o que não ocorre no aqüífero cristalino fissural, existindo assim. incompatibilidade entre os SI da gibsita e dos carbonatos.

Os óxidos e hidróxidos de ferro (hematita e goetita) apresentam índices de saturação positivos indistintamente, tanto nas coberturas quanto no aqǘf́ro cristalino fissural, fato que não ocorre com o carbonato de ferro (siderita) que está subsaturado nos dois sistemas aqüíferos dos pontos estudados. Todavia, em algumas regiões de pântanos e brejos de Salvador as águas subterrâneas podem apresentar precipitação de carbonatos de ferro (siderita). Este fato está evidenciado na forte correlação linear negativa com os valores de Eh (Nascimento 2008).

É fato notório a existência nos poços tubulares de Salvador, a formação de crostas ferruginosas (ferrugem) tanto nos poços que captam água nas coberturas quanto no embasamento fissural .

O manganês apesar de ocorrer frequentemente com teores relativamente altos nas águas subterrâneas, encontra-se dissolvido sob a forma de $\mathrm{Mn}^{2+}$ não tendo condições de se precipitar a sua fase sólida sob a forma de pirolusita e manganita. Encontra-se subsaturado nas águas subterrâneas tanto nas coberturas quanto no embasamento cristalino fissural, além do $\mathrm{pH}$ sempre inferior a 8,0 não favorecer a sua precipitação na área estudada.

Com isto, o modelo hidrogeoquímico proposto para a área é, portanto, de uma supersaturação de ferro nas águas das coberturas e do embasamento cristalino fissural indistintamente. Os processos de supersaturação das águas com carbonatos só se verifica no embasamento cristalino devido a maior concentração de bicarbonatos e as condições ambientais favoráveis. O manganês encontra-se dissolvido não tendo condições físico-quimicas de precipitar-se na sua fase sólida sob a forma de manganita e pirolusita, enquanto o alumínio se encontra em condições de supersaturação somente ao nível das coberturas regoliticas, precipitando-se sob a forma de gibsita.

Agradecimentos Os autores expressam os seus agradecimentos à Embasa-Empresa Baiana de Águas e Saneamento pelo financiamento dessa pesquisa, bem como, pelas análises químicas realizadas em seus laboratórios.

\section{Referências}

AMERICAN PUBLIC HEALTH ASSOCIATION (APHA). 1998. Standards Methods for the Examination of water and Wastewater, $4500 \mathrm{Cl}-\mathrm{A} / \mathrm{B}$. 20th edition. Washington D.C., 382p. www.Standard Methods.org.

Barbosa J.S.F., Gomes L.C.C., Dominguez J.M.L.,Cruz S.A.S., Souza J.S. 2005. Petrografia e litogeoquímica das rochas da parte oeste do Alto de Salvador, Bahia. Revista Brasileira de Geociências, 35(4):09-22.

Deutsch W.J. 1977. Groundwater geochemistry: fundamentals and applications to contamination. Lewis Publishers, Boca Raton, 220p.

INSTITUTO BRASILEIRO DE GEOGRAFIA E ESTATÍSTICA (IBGE) 1999. Folha SD-24 Salvador: potencial dos recursos hídricos. Rio de Janeiro, 236p.

Martin L. 1980. Mapa geológico do quaternário costeiro do Estado da Bahia: texto explicativo. Salvador, Secretaria das Minas e Energia, Produção Mineral, 1 mapa geológico, escala 1:250.000, 57p.
Mason B.H. 1971. Princípios de geoquímica. São Paulo, Editora da Universidade de São Paulo, 401p.

Nascimento S.A. de M. 2008. Diagnóstico hidrogeologico, hidroquímico e da qualidade da água do aqüifero freático do Alto Cristalino de Salvador-Bahia. Tese de Doutoramento, Instituto de Geociências, Universidade Federal da Bahia, 195p.

Piper A.M. 1944. A graphic procedure in the geochemical interpretation of water anallysis. Transactions American Geophysical Union, 25:911-923.

North Dakota State University Department of Geosciences. 2007. Web-Phreeqc: Aqueous Geochemical Modeling. Disponível em: http://www.ndsu.nodak.edu/webphreeq/. Acessado em 10 de julho de 2007.

Manuscrito ID 12352

Submetido em 25 de setembro de 2008 Aceito em junho de 2009 